\title{
Tumor de Brenner Benigno e Maligno na mesma Paciente: Relato de Caso
}

\author{
Brenner's Benign and Malignant Tumor: A Case Report \\ Antônio Chambô Filho, Danielle Chambô, Fabio Leal Laignier Borges, \\ Luiz Calice Cintra, Rolney Scardini
}

\begin{abstract}
RESUM0
Na grande maioria das vezes, o tumor de Brenner é pequeno, unilateral e benigno. Seu diagnóstico só pode ser confirmado após o exame anatomopatológico, que microscopicamente apresenta ninhos ou colunas de células epiteliais de transição numa matriz fibromatosa. As células epiteliais apresentam sulco longitudinal característico de "grão de café" e podem apresentar transformação carcinomatosa. É descrito o caso de paciente menopausada com sangramento vaginal, com massa abdominal palpável, submetida a tratamento cirúrgico, com diagnóstico histopatológico de tumor de Brenner bilateral, sendo maligno de um lado e benigno do outro. Atualmente está com 3 anos de sobrevida, sem sinais de recorrência da doença após tratamento cirúrgico exclusivo.
\end{abstract}

PALAVRAS-CHAVE: Ovário: câncer. Tumor de Brenner. Hiperplasia de endométrio.

\section{Introdução}

O primeiro caso de tumor de Brenner maligno foi publicado em 1945, por von Numers ${ }^{1}$. Em 1971, Roth et al. ${ }^{2,3}$ identificaram um tumor de Brenner proliferativo, correspondente a uma neoplasia de malignidade limítrofe.

Os tumores de Brenner são neoplasias fibroepiteliais constituídas de tecido derivado do estroma ovariano e por células epiteliais, poliédricas ou redondas, do tipo urotelial ou de transição $0^{4,5}$. Essas células contêm um pequeno núcleo em fenda ou em forma de "grão de café", podendo haver grupamentos dessas células e configurar estruturas denominadas nichos ou ninhos $^{6}$. Os nichos epiteliais podem formar glândulas ou cistos, revestidos de células planas, cubóides ou cilíndricas; às vezes há células escamosas ${ }^{6}$.

Os tumores de Brenner representam de 2 a $3 \%$ de todos os tumores ovarianos ${ }^{6}$. A maioria destes tumores de Brenner são benignos; 2 a 5\% são malignos ao passo que outros 2 a $5 \%$ apresentam histologia limitrofe ${ }^{6}$. São classificados como malignos quando além do componente benigno do tu-

Correspondência:

Antônio Chambô Filho

R. Constante Sodré 1027, ap.301 - Praia do Canto 29055-420 - Vitória - ES mor de Brenner, ou seja, nicho de epitélio de transição em meio ao estroma fibroso, apresentam carcinoma de células de transição ${ }^{1}$. Há transformação carcinomatosa com aparecimento de células escamosas ou de células de transição. Guando somente o componente maligno é visto, o tumor é considerado carcinoma de células transicionais de ovário, portanto mais agressivo que tumor de Brenner. Quando há associação com carcinoma mucinoso, o tumor deve ser considerado misto, dependendo da quantidade de elementos brennerianos ${ }^{5}$.

Foram relatados tumores de Brenner de outra localização. Rashid e Fox ${ }^{7}$ relataram um caso de tumor de Brenner da vagina em mulher pósmenopausada que se apresentou como pólipo vaginal que foi ressecado.

Johnson et al. ${ }^{8}$, relataram um caso de carcinoma escamoso metastático de colo uterino estádio IIB para um tumor de Brenner ovariano.

\section{Relato do Caso}

D.C.S., 60 anos, parda, menopausada há 8 anos, gesta X para X. Chegou ao Serviço de Ginecologia da Santa Casa de Misericórdia de Vitória em setembro de 1999 com queixa de sangramento vaginal. Ao exame, observava-se vagina e colo 
atróficos, sangramento de moderada intensidade fluindo pelo orifício externo do colo. Ao exame ginecológico, o útero estava aumentado de volume, palpável na altura da cicatriz umbilical e com contornos mal definidos.

À ultra-sonografia abdominal observou-se útero com volume de $246 \mathrm{~cm}^{3}$ e massa sólida delimitada de $936 \mathrm{~cm}^{3}$ junto à parede posterior. Os ovários não eram visualizados e o endométrio apresentava espessura de $4 \mathrm{~mm}$.

Outros exames como hemograma, provas de função hepática e renal normais, assim como radiografia de tórax.

A conduta foi laparotomia exploradora, durante a qual foi feito o lavado peritoneal com coleta de líquido. Foi observada tumoração ovariana esquerda com cerca de $25 \mathrm{~cm}$ de diâmetro e tumoração ovariana direita com cerca de $10 \mathrm{~cm}$ de diâmetro. O útero apresentava tamanho e aspecto normais. Foi efetuada histerectomia total, salpingooforectomia bilateral e omentectomia (Figura 1). O diagnostico histológico foi tumor de Brenner de $6,5 \mathrm{~cm}$ no ovário direito e tumor de Brenner maligno de $22 \mathrm{~cm}$ no ovário esquerdo ( $\mathrm{Fi}$ gura 2), e ausência de comprometimento neoplásico da trompa uterina e do omento. O líquido peritoneal não apresentava células neoplásicas o estadiamento patológico foi pT1.

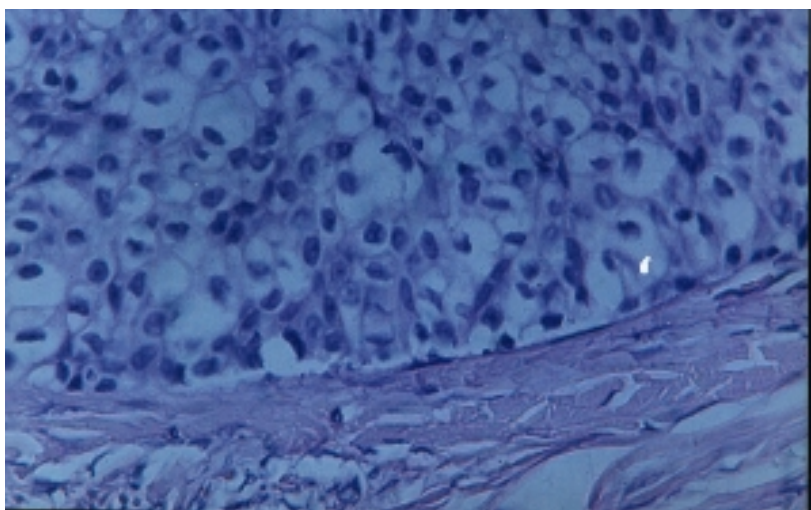

Figura 1 - Microscopia do tumor de Brenner maligno. Epitélio de transição com polarização desorganizada. HE400X.

No pós-operatório a paciente foi encaminhada ao Serviço de Oncologia Clínica, onde foi submetida à prova de função renal e hepática, radiografia de tórax e tomografia computadorizada de abdome e pelve, sem nenhum sinal de metástase. Optou-se por acompanhamento trimestral, com realização desta propedêutica no primeiro ano e semestral após segundo ano. Não foi realizada quimioterapia, devido à baixa eficácia para este tumor. A paciente encontra-se em acompanhamento há 3 anos, sem sinais de evolução da doença.

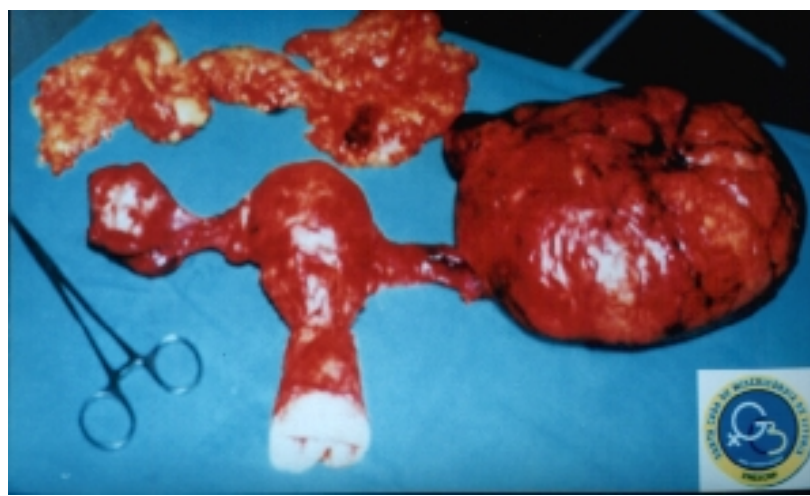

Figura 2 - Macroscopia: Tumoração com cerca de $22 \mathrm{~cm}$ bocelada no ovário esquerdo tumoração com $6,5 \mathrm{~cm}$ no ovário direito, útero aumentado de volume e omento sem sinais de metástase.

\section{Discussão}

Os tumores de Brenner são de origem fibroepitelial, e são compostos por nichos de um epitélio de transição (semelhante aos que revestem a bexiga) infiltrando um estroma fibroso denso $^{9}$. Em aumento de 1000 vezes, estas células epitelióides revelam disposição em "grãos de café" causada por um sulco longitudinal dos núcleos ${ }^{3}$.

Menos freqüentemente, os nichos contêm microcistos ou espaços glandulares revestidos por células colunares que secretam mucina. Por motivos não esclarecidos, os tumores de Brenner são encontrados algumas vezes nos cistoadenomas mucinosos. Classicamente os tumores de Brenner são benignos e endocrinologicamente inertes, mas nas últimas décadas tem aumentado o número de sua versão maligna e associação com hiperplasia endometrial pós-menopausa ${ }^{10}$ e outros associados a virilização ${ }^{6}$.

As formas malignas são freqüentemente sólidas ou, ainda, císticas com áreas sólidas. Podem apresentar diferenciação escamosa nos blocos sólidos de células que infiltram o estroma. Para seu diagnostico é fundamental amostragem histológica rica para tentar identificar o componente benigno ou "borderline" do tumor de Brenner e assim concluir o diagnóstico ${ }^{3}$. Na ausência do componente de Brenner a neoplasia será considerada carcinoma de células transicionais de ovário, que junto ao adenocarcinoma pouco diferenciado são os principais diagnósticos diferenciais ${ }^{5}$.

Como são geralmente pequenos, unilaterais (bilateralidade em 10\% dos casos) e benignos, não apresentam manifestações clínicas e são geralmente achados cirúrgicos inesperados. Os maiores podem pesar até $25 \mathrm{~kg}$, com sintomas semelhantes aos dos grandes fibromas ${ }^{11}$. Ocorrem geralmente em mulheres na quinta e sexta década. Sua remo- 
ção é suficiente em caso de tumor de Brenner benigno, porém em casos malignos, a histerectomia com ooforectomia bilateral é preferida ${ }^{12}$.

Seria importante separação dos tumores de células transicionais em tumores de Brenner e carcinomas de células transicionais, diferenciando estes últimos da forma maligna do tumor de Brenner, diante das diferenças no comportamento biológico. Os tumores de Brenner, por sua vez, como os epiteliomas, subdividem-se em forma benigna, de baixo potencial de malignidade, e maligna ${ }^{13}$. Os carcinomas de células transicionais são morfologicamente similares aos correspondentes do trato urinário e não apresentam componente do tipo Brenner na lesão. Podem coexistir com áreas de diferenciação serosa, endometrióide ou indiferenciada, que devem ser inferiores a 50\% na composição neoplásica ${ }^{13}$. O carcinoma de células transicionais, desde que se respeitem seus critérios histológicos diagnósticos, são mais sensíveis às drogas quimioterápicas usualmente utilizadas em neoplasias ovarianas $^{12}$. Apresentam-se freqüentemente em estádios mais avançados do que o tumor de Brenner maligno e têm evolução clínica mais agressiva. Nestes blastomas é importante a avaliação histológica das metástases. Em neoplasias metastáticas com predomínio do componente de células transicionais a sobrevida de 5 anos livre de doença ocorre em 56\% dos casos, comparando com os $7 \%$ das pacientes cujas metástases mostram outros tipos histológicos ${ }^{13}$.

Os tumores de Brenner apresentam histogênese ainda controversa, gerando várias explicações, como a de Meyer, que acredita que eles se originem do epitélio superficial dos restos de Walthard. Estas são coleções das chamadas células indiferentes, que se apresentam sob forma de placas escamosas ou de pequenos grupos de ácinos glandulares, na superfície ou logo abaixo dela no ovário, trompa ou nos ligamentos uterinos ${ }^{2,4,11,13}$.

O tumor de Brenner maligno pode se apresentar como produtor de hormônio, segundo Joh et al. ${ }^{9}$, que observaram hiperestrogenismo em mulher de 79 anos, em cujo soro e urina pré-operatórios se encontravam altos índices de estrogênios e baixo índice de hormônio luteinizante (LH) e de hormônio folículo-estimulante (FSH); histologicamente, hiperplasia endometrial atipica sugeria a presença de hiperestrogenismo. A redução em soro e urina dos niveis de estrogênio e o aumento no soro do LH e das concentrações de FSH depois da remoção do tumor com diagnóstico de tumor de Brenner confirmaram que o tumor estava sintetizando estrogênio ${ }^{9}$.

Em alguns casos é observada associação com hiperplasia pós-menopausa do endométrio e adenocarcinoma, o que reforça a necessidade de propedêutica endometrial nestes $\operatorname{casos}^{13}$.

A histerectomia total mais salpingooforectomia bilateral representa o principal tratamento dos tumores de Brenner benignos e dos malignos confinados aos ovários. Alguns estudos mostraram que a radioterapia não melhora o prognóstico, enquanto a quimioterapia não teve sucesso para este tipo histológico em estádios avançados. A sobrevida de 5 anos em pacientes com tumor de Brenner maligno é rara, sendo de $65 \%$ no estádio I e $35 \%$ no estádio II $^{12}$.

\section{ABSTRACT}

Brenner's tumor is small, unilateral and benign. Its diagnosis can only be confirmed by the anatomomicopathological examination, that on microscopy presents nests or columns of transition epithelial cells in a fibromatous matrix. The epithelial cells present a characteristic longitudinal "coffee bean" furrow and can undergo carcinomatous transformation. We present a case of a menopausal patient with vaginal bleeding, and a palpable abdominal mass. She was submitted to surgical treatment (total hysterectomy, bilateral oophorectomy and omentectomy) with the histopathological diagnosis of Brenner's bilateral tumor, being malignant on one side and benign on the other. After surgical treatment she is now alive for three years and free of disease.

KEYS WORD: Ovary: Brenner's malignant tumor. Ovary tumor. Endometrial hyperplasia.

\section{Referências}

1. von Numers C. Contribution to the case knowledge and histology of the Brenner tumor. Do malignant forms of the Brenner tumor also occur? Acta Obstet Gynecol Scand 1945; 25 (Suppl 2):114-27.

2. Roth LM, Dalllenbach-Hellweg G, Czernobilsky B. Ovarian Brenner tumors. I. Metaplastic, proliferating, and of low malignant potential. Cancer $1985 ; 56: 582-91$.

3. Roth LM, Czernobilsky B. Ovarion Brenner tumors. II. Malignant. Cancer 1985; 56:592-601.

4. Urbano U, Facchini V, Gadducci A, Basile AG, Pellegrini F. Brenner's tumor. Observations on six cases. Eur J Gynaecol Oncol 1984; 5:207-13. 
5. Austin RM, Norris HJ. Malignant Brenner tumor and transitional cell carcinoma of the ovary: a comparison. Int J Gynecol Pathol 1987; 6:29-39.

6. Lima GR, Lima AO, Baracat EC, Vasserman J, Burnier M Jr. Virilizing Brenner tumor of the ovary: case report. Obstet Gynecol 1989; 73:895-8.

7. Rashid AM, Fox H. Brenner tumour of the vagina. J Clin Pathol 1995; 48:678-9.

8. Johnson TL, Keohane ME, Danzey TJ, Hicks ML. Squamous cell carcinoma of the cervix metastatic to an ovarian Brenner tumor. Mod Pathol 1995; 8:307-11.

9. Joh K, Aizawa S, Ohkawa K, Dohzono H, Aida S, Ohgoshi E. Case report of a malignant Brenner tumor with hyperestrogenism. Pathol Int 1995; 45:75-84. (aparece no texto após a referência 16)

10.Scully RE. Brenner tumors. In: Hartman WH, editor. Atlas of tumor pathology. Tumors of the ovary and maldeveloped gonads. Washington, DC: Armed Forces Institute of Pathology; 1979.
11. Ming SC, Goldman H. Hormonal activity of Brenner tumors in postmenopausal women. Am J Obstet Gynecol 1962; 83: 666-73.

12.Mondolfo R, Cavalieri A, Egami M. Tumor de Brenner: relato de um caso clínico e revisão da literatura. Klinikos 1988; 4:44-7.

13. Yamamoto R, Fugita M, Kuwabara M, et al. Malignant Brenner tumors of the ovary and tumor markers: case reports. Jpn J Clin Oncol 1999; 29:308-13.

14.MacKay DG, Pinkerton JHM, Hetig AT, Danziger S. The adult human ovary: a histochemical stud. Obstet Gynecol 1961; 1813-39.

15. Carvalho FM, Souen JS, Carvalho JP, Filassi JR, Pinotti JA. Carcinoma do ovário: novas definições e atualização classificatória. Rev Ginecol Obstet 1993; 4:122-7.

\title{
V Curso de Imagem em Ginecologia e Obstetrícia da SGORJ
}

\section{5 de março de 2003}

\section{Centro de Convenções do CBC - RJ}

\author{
Informações: \\ SGORJ$$
\text { (21) 2285-0892 - 2205-2032 }
$$$$
\text { sgorj@gbl.com.br }
$$ 